\title{
Medical Personnel and Life Expectancy: New Evidence from Taiwan
}

\author{
Ya-Hui Huang ${ }^{1} \cdot$ Chien-Chiang Lee $^{2} \cdot$ Chun-Ping Chang $^{3}$
}

Accepted: 28 August 2015/Published online: 4 September 2015

(C) Springer Science+Business Media Dordrecht 2015

\begin{abstract}
Waldmann (Q J Econ 107:1283-1302, 1992) established long ago that being improvements in health, medical personnel are the valued input factor of the health production function. Previous research, however, has generally ignored the importance of medical personnel in the health production function and has almost exclusively focused on health expenditure. Thus, the motivation behind this study is to identify the relationship between two health indicators, namely medical personnel, i.e., registered nurses and physicians, and average life expectancy in Taiwan. From the empirical results, we find that there is a long-term equilibrium relationship between the two variables and that medical personnel play a crucial role in the medical care system. Finally, the forecast error variance in life expectancy is mainly explained by itself. Moreover, medical personnel have a positive initial impact on life expectancy, and similar innovations are discovered vice versa in the impulse response functions. Some policy implications can be obtained via our empirical results.
\end{abstract}

Keywords Life expectancy $\cdot$ Medical personnel $\cdot$ Cointegration $\cdot$ Impulse response function - Taiwan

JEL Classification $\mathrm{I} 12 \cdot \mathrm{C} 22 \cdot \mathrm{H} 56$

Chien-Chiang Lee

cclee@cm.nsysu.edu.tw

Ya-Hui Huang

yhhuang@isca.vghks.gov.tw

Chun-Ping Chang

cpchang@g2.usc.edu.tw

1 Nursing Department of Kaohsiung Veterans General Hospital, Kaohsiung, Taiwan

2 Department of Finance, National Sun Yat-sen University, Kaohsiung, Taiwan

3 Department of Marketing Management, Shih Chien University, Kaohsiung, Taiwan 


\section{Introduction}

On April 24th, 2003, the Taipei City Government decided to close off the Taipei Municipal Ho Ping Hospital and quarantine patients and staff at the facility for at least two weeks in an attempt to contain an outbreak of the potentially fatal severe acute respiratory syndrome (SARS) in Taiwan. Unfortunately, on May 1, two people died. They had had contracts with the Taipei Municipal Hoping Hospital; one is the hospital's 48-year-old head nurse- Chen Ching-chiu. Chen had worked at Hoping Hospital for 20 years. She was among the most valued medical personnel of the hospital but died performing the duties that she invested everything in.

\section{The China Post staff, Taipei, Taiwan, May, 2, 2003}

The demand for medical inputs is derived from the presumed connection between medical care and health (Grossman 1972). In the past, numerous scholars viewed that the major issues in the domain of health included lifestyle, environment, and biotype, particularly when it came to the demand for medical care. However, in terms of health outcomes, health economists are interested in the impact of medical care on the health status of the population for a long time. ${ }^{1}$ To be sure, medical care, in particular the services provided by medical personnel, is highly valued by virtue of the improvements in health it enables (Waldmann 1992). This raises a series of research discussions later in this paper.

Self and Grabowski (2003) have suggested that a time series dimension in this field would greatly add to the understanding of relevant health care relationships and resolve the limitations of previous analyses. This paper attempts to review their achievements and contributions vis-à-vis the long-run equilibrium and the short-run dynamic relationship between health indicators and medical personnel in Taiwan during the 1968-2013 period.

Unlike previous papers, ${ }^{2}$ however, this paper makes some distinct innovations with regard to the construction of the methodology we employ. First, in the past, most studies have focused on health expenditures as a separate input to life expectancy. Instead, based on Waldmann's (1992) findings, we substitute medical personnel (henceforth MEP), comprised of registered nurses and physicians, for medical expenditures. ${ }^{3}$ Next, we use life expectancy at birth (henceforth ELF) as the measure of health because it includes the most comprehensive measures that combine both the mortality and morbidity facets of health. Furthermore, ELF, accounting for other health-related and non-health-related factors, can affect health and is usually adopted by the World Health Organization (WHO) (Self and Grabowski 2003). ${ }^{4}$ Another unique approach that this research takes is that we apply large

\footnotetext{
1 The other factors include socioeconomic factors (Lantz et al. 1998; Borg and Kristensen 2000), lifestyle (Kenkel 1995; Contoyannis and Jones 2004) and environmental factors (Fuchs 1986; McGinnis and Foege 1993), among others.

2 Almost all of them center around securing a healthier labor force, increasing productivity, accumulating human capital, and increasing economic growth (Newhouse 1977; Wheeler 1980; Currais and Rivera 1999; Rivera and Currais 2003; Bloom et al. 2004; Shaw et al. 2005). The main conclusion is that health has a positive and significant effect on economic growth though some authors argue that health does not play a critical role in promoting economic growth (Easterly and Rebelo 1993).

3 Waldmann (1992) used the number of doctors (nurses) per thousand in log as the proxy consumption of medical services to measure more demand of the medical services when the rich are richer. Both indexes are usually used by international organizations and governmental agencies, such as the World Health Organization (WHO) and the Organization for Economic Co-operation and Development (OECD).

${ }^{4}$ Soubbotina and Sheram (2000) pointed out that life expectancy is often cited as the overall measure of a population's quality of life because, as an indicator, it also indirectly reflects many aspects of people's
} 
time series empirical tests, including cointegration tests and the error correction model (henceforth ECM), to investigate the long-run and short-run dynamic relationships between MEP and ELF. This procedure has one distinct advantage, by which we are able to determine the influence of nurses and physicians on the overall well-being of the population at large and vice versa (Chen et al. 2014). Apart from this, while the MEP-ELF relationship has previously been investigated using conventional methods, it has never been studied via econometric techniques before. Finally, this study employs variance decomposition which is attributed to its own innovations and to the shocks in other variables in the system through the proportion of forecast error variance for each variable. The effect of a one-time shock to one of the innovations in the current and future values of the endogenous variables is tested using impulse response function traces.

Both physicians and nurses are essential resources in medical treatment and care systems and assume the major responsibilities for citizens' health. This serves as the motivation for the present study which investigates the effects of the provision of medical personnel on Taiwanese life expectancy. Advances in medical research and better health care services and facilities, as well as other factors, have enabled people to live longer. Increased life expectancy, however, brings new challenges, such as greater demands on acute care services (Rivera and Currais 2003). Grossman (1972) suggested that there is a mutual influence between health needs and medical care. This makes it necessary to analyze the existence of a feedback effect between health status and medical resources, in particular medical personnel-physicians and nurses. If the causal relationship between life expectancy and medical personnel is bi-directional, then this will have the detection of different appearance which has been attracting the interest of health professor and make comparisons for the health expenditure. Many policy implications can also emerge from the results.

Taiwan provides an ideal platform for research. First, some interesting facts make it worthy to investigate the situation in Taiwan in light of some historical facts and some insight from previous studies. For instance, Chiang (1997) argued that under considerable domestic political pressure, the Taiwan government implemented a compulsory universal health insurance scheme in 1995. By the end of its inaugural year, the scheme covered $92 \%$ or more of the population, and the utilization pattern of the newly-insured closely approximated that of the previously insured. The scheme, nevertheless, did not efficiently make use of health care resources probably, and this may actually cause the situation to be worsen. For this reason, recently, Lu and Hsiao (2003) have pointed out that Taiwan's hospitals have developed large outpatient departments and affiliated clinics for primary care; they argued that Taiwan offers an opportunity to study how an advanced economy can structure its health care system to advance societal goals, not harm them.

Furthermore, a better justification for this sample country is that Taiwan successfully managed the severe acute respiratory syndrome (SARS) crisis in 2003, for this well-known disease storm in whole world, feature further the medical personnel's materiality. Hence, an individual country analysis can be careful as well as right exact to keep track of the national characteristic; besides this, it offer further to inference accurately. For example, Jones (1995) proposes that time series studies offer important advantages over crosscountry. Arestis et al. (2001) indicate that this method can provide useful insights into

Footnote 4 continued

welfare, including the quality of their environment, their level of income, the quality of their nutrition and their access to safe water, sanitation, and health care. 
differences of this relationship across countries and may illuminate important details hidden in averaged-out results.

We discuss the methodological issues and their effects on our results in the remainder of the paper. On the basis of our findings, the critical policy implication are delivered: given the cointegration relationships between life expectancy at birth and the number of registered nurses and physicians in Taiwan, the Taiwan government still has to keep on improving the public health care program meanwhile to train more efficient medical personnel; paying greater attention to carefully establish and enhance medical treatment policy when higher life expectancy is expected in Taiwan. We finally suggest that the administrative policy should provide more on-going training to medical personnel, better control a low patient-to-health care worker ratio, and then ensure a high standard of medical care.

The next section of this paper discusses the related literature. Section 3 then demonstrates our methodology. In Sect. 4, we present the results, with an emphasis on the effects of medical personnel, namely nurses and physicians, on life expectancy. Concluding remarks and implications are contained in the final section.

\section{Literature Review}

The literature as Soubbotina and Sheram (2000) advocate that two factors are the most important for increasing national and regional life expectancies: improvements in medical technology and the development of and better access to public health services. Kerry (2009) proposes that increasing the life expectancy of the population combines with increasing the GDP per capita growth in Japan. Even among these, personnel in medical treatment facilities play an indispensable role. It cannot be denied that an efficient and effective health care system requires the specialized skills of a team of licensed medical personnel-primarily made up of physicians and nurses. An effective health care system represents a perfect program with short- and long-term goals, and it requires skilled services over specified periods of time (Mullner and McNeil 1986; Kindig 1997). As Soubbotina and Sheram (2000) have put it, in cases where the inherent complexity of a service required by a patient can only be safely and effectively administered with the direct supervision of licensed health care professionals. The service can be considered a skilled service provided by medical personnel.

Waldmann (1992) performed a cross-country analysis with respect to the relationships between income distribution and infant mortality for 41 countries and found that infant mortality is higher when the income of the rich is higher due to an inequality in the distribution of income. He considered and tested several possible explanations, and the most important factor is the provision of medical services used as proxy for the number of doctors and nurses per capita. Wikström et al. (2013) pointed out that the descriptions for pain scales by medical personnel not only contribute to the understanding of patient's postoperative pain but also to ensure patient understanding about variations in pain ratings. Along the same lines, in this study, we empirically investigate what role medical personnel play in enhancing citizens' health in Taiwan.

Several studies have focused on major health care issues in developing countries, such as Anand and Ravallion (1993) is for Sri Lanka, Bhargava (1997) for Rwanda, Bloom and Xingyuan (1997) for China, Chiang (1997) for Taiwan, Fayissa and Gutema (2005) for Sub-Saharan Africa, and Miller and Freeh (2000), Rivera and Currais (2003), and Shaw 
et al. (2005) for developed countries like those in the Organization for Economic Cooperation and Development (OECD). Unfortunately, the common point of these conventional studies is that they use medical expenditures as the proxy variable for the health input factor. Worth noting is that Kindig (1997) pointed out the inadequacies of such an approach and rightly discussed the failure of traditional market forces, the impact of managed care and the lack of relationship between health expenditures and health outcomes in the United States.

The real question is whether health spending can fully explain variations in the state of national health. There are several sound arguments against government intervention in health care. For one, Rivera and Currais (2003) showed that it is hard to determine the link between health expenditure and the state of national health. They considered doubt on any direct relation for increased health spending and improvements in health especially in developing and dictatorial countries. Thornton (2002) reported that in the U.S., the most important factors that influence the death rate are related to socioeconomic status, medical services provided by nurses and physicians as well as to lifestyle, but not medical expenditures. In their penetrating criticism of health expenditures as the important variable, Self and Grabowski (2003) have asserted that expenditures do not really reflect the quality of health care and that it is medical personnel that are at the forefront of medical services. One interesting case is the predicament of reduced government intervention in health care in China on account of inefficiency in the allocation of medical resources (Bloom and Xingyuan 1997). On the other hand, Chiang (1997) used Taiwan as an example of the lack of efficiency with regard to public health spending, where health care suffered due to the compulsory universal health insurance scheme introduced in 1995; Taiwan finally experienced a financial crisis from gradually increasing the costs of medical care.

By the late 1990s, most countries in the world were enjoying a much higher life expectancy because of their higher real GDP per capita. This upward shift in longevity testifies to the power of medical advances, broadly defined to include interventions delivered by medical personnel as well as advances in public health knowledge. Generally speaking, governments of both developed and developing countries have all made heavy investments to improve health care practices, better train medical personnel, build clinics, hospitals and other facilities and provide medical care (Soubbotina and Sheram 2000). Therefore, while restricting to a particular country or region, it is helpful to increase the availability of skilled medical personnel in medical organizations to sustain improvements in overall health care. In one case study in Spain, Younga and Rodriguez (2005) have recently employed a methodology that uses structural indicators-including medical personnel, schools, and hotels, and they have adopted factor analysis and regressions to identify major types of social organizations and their correlations with the life expectancy of men and women. They have found that the structural indicators significantly and positively predict both male and female life expectancy in metropolitan areas and commercial provinces in Spain.

Auster et al. (1969) were the first to study a population production function for health: a regression of state-level mortality rates on medical care and environmental variables. Coile et al. (2002) have emphasized that life expectancy has a high correlation with human behavior, economic development, fertility rate and human capital investment, and so forth (see also Rivera and Currais 2003). Barlow and Vissandjee (1999) as well as Fayissa and Gutema (2005) have reported that based on a 1990 through multivariate cross-national analysis, literacy, per capita income and access to safe water supplies have significantly positive effects on life expectancy at birth and that per capita health expenditures and the urbanization rate appear to be weak determinants. Since the most common indicator that 
has been used in previous studies is life expectancy (Rivera and Currais 2003), we select it as the health variable in this paper. It is also usually adopted by the WHO.

Studies, related to the association between the medical personnel and average life expectancy outcomes, have found as richness and diversity. For example, Hertz et al. (1994) used data from United Nations sources which are available on a maximum of 66 countries; they found that the medical resource availability, health and nutrition, gross national product present its significant prediction of life expectancy at birth. Additionally, Nolte et al. (2002) assessed the impact of medical care on changes in mortality in East Germany and Poland before and after the political transition in the period of 1980-1997, from which the quality of medical care and changes in the health care system related to the political transition were associated with improvements in life expectancy in east Germany and Poland. This links with Chernichovsky and Anson (2005), who argue that the distribution of life expectancy across localities in Israel reflects the distribution of those localities' socio-economic condition index, and the distribution of medical services among the Jews and Israeli Arabs in Israel, especially for those disparities in life expectancy among Jews and Arabs living in poorer communities, mainly dependents on the numbers of physician and nurses.

Furthermore, Young and Rodriguez (2005) used factor analysis in a regression model and report that organizational items such as schools, hotels, and medical personnel can be employed to predict life expectancy of men and women in the 50 urban, commercial, industrial, and tourist provinces of Spain. This consistent with the work of Hickson (2009), who provided a justification for the increase in health care-including the training of physicians, establishing an increasing number of medical schools, manpower development plans for supporting health personnel etc. when it is extended to incorporate the increase in the life expectancy of the population of Japan. Ssozi and Amlan (2015) hence examined the effectiveness of health expenditure from 1995 to 2011 across 43 nations of SubSaharan Africa, employing the General Method of Moments technique. They find that those countries equipped with better healthcare systems due to enhancing health-seeking behaviors and medical care usually have better life expectancy.

\section{Methodology}

An example of using the generic approach to estimate health production and to input equations is the one by Rosenzweig and Schultz (1983). Kenkel (1995) estimated health production functions using several output measures. In estimating the impact of lifestyle on adult health from British data, Contoyannis and Jones (2004) have estimated a recursive empirical specification consisting of a health production function. Following these health production models and consistent with Waldmann's (1992) contention that medical personnel is the most important input factor for improvements in health, we use the following bivariate vector autoregression (VAR) model to test the relationship between life expectancy and medical personnel:

$$
E L F_{t}=f\left(M E P_{t}\right)
$$

where ELF is the average life expectancy at birth, and MEP is medical personnel per thousands of registered nurses and per thousands of physicians. 


\subsection{Unit Root Tests}

Nelson and Plosser (1982) argued that many macroeconomic time series contain unit roots dominated by stochastic trends and that the cointegration test of the examined variables initially requires testing for the existence of a unit root in each individual time series. Thus, the integration order of the variables must be verified since the causality tests must determine whether the variables have the same integration order or not. Unit roots are important when examining the stationarity of a time series because a non-stationary regressor invalidates many standard empirical results (Lee et al. 2014). In this research, we examine the integration order of all of the variables by applying two unit root tests to obtain more accurate test results with intercept and an intercept as well as a trend. The tests that we use are the Augmented Dickey-Fuller (henceforth the ADF) and the Dickey-Fuller test with Generalized Least Square (DF-GLS; Elliott, Rothenberg, and Stock 1996, denoted asERS 1996). The ADF test constructs a parametric correction for higher-order correlation by assuming that the $y$ series follows an AR $(k)$ process and by adding the lagged difference terms of the dependent variable to the right hand side of the test regression when comparing with Dickey and Fuller (1979) test. Thus:

$$
\Delta y_{t}=\alpha_{0}+\alpha_{1} t+\alpha_{2} y_{t-1}+\sum_{j=1}^{k} \alpha_{j} \Delta y_{t-j}+\epsilon_{t},
$$

where $y_{t}$ is the specified variable in $\log$ at time $\mathrm{t}$; the variable $\Delta y_{t-1}$ expresses the first differences; and $\epsilon_{t}$ is the error term. All the coefficients in Eq. (2) are estimated. The null and alternative hypotheses may be written as:

$$
\begin{array}{lc}
\mathrm{H}_{0}: & \alpha_{2}=0 \\
\mathrm{H}_{1}: & \alpha_{2}<0
\end{array},
$$

and evaluated using the conventional $t$-ratio for $\alpha_{2}, t_{\alpha_{2}}=\hat{\alpha}_{2} /\left(\operatorname{se}\left(\hat{\alpha}_{2}\right)\right)$, where $\hat{\alpha}_{2}$ is the estimate of $\alpha_{2}$, and $\operatorname{se}\left(\hat{\alpha}_{2}\right)$ is the coefficient standard error. The most optimal lagged term for the model is selected by using the Schwartz (1987) and the Bayesian Information criterion (SBC), as suggested by Ng and Perron (1995).

To improve upon the low power in a small sample, Elliot et al. (1996; ERS) proposed local to unity Generalized Least Squares (GLS) detrending of the data. ERS defined a quasi-difference of $y_{t}$ that depends on the value $\alpha_{2}$ that represents the specific point alternative against which we wish to test the null:

$$
d\left(y_{t} \mid \alpha_{2}\right)=\left\{\begin{array}{ll}
y_{t} & \text { if } t=1 \\
y_{t}-\alpha_{2} y_{t-1} & \text { if } t>1
\end{array} .\right.
$$

Next, we consider an OLS regression of the quasi-differenced data $d\left(y_{t} \mid \alpha_{2}\right)$ on the quasi-differenced $d\left(\chi_{t} \mid \alpha_{2}\right)$ :

$$
d\left(y_{t} \mid \alpha_{2}\right)=d\left(\chi_{t} \mid \alpha_{2}\right) \delta\left(\alpha_{2}\right)^{\prime}+\eta_{t}
$$

where $\chi_{t}$ contains either only a constant or a constant and a trend considered simultaneously. Let $\hat{\delta}\left(\alpha_{2}\right)$ be the OLS estimates from this regression. We now define the GLS detrended data, $y_{t}^{d}$, using the estimates associated with $\bar{\alpha}_{2}$ and $y_{t}^{d}=y_{t}-\chi_{t}^{\prime} \hat{\delta}\left(\alpha_{2}\right)$. Then the DF-GLS test involves estimating the standard ADF test Eq. (2), after substituting the GLS detrended $y_{t}^{d}$ for the original $y_{t}$ : 


$$
\Delta y_{t}^{d}=\beta_{0} y_{t-1}^{d}+\sum_{j=1}^{k} \beta_{j} \Delta y_{t-j}^{d}+v_{t} \quad j=1, \ldots, k
$$

Note that since $y_{t}^{d}$ is detrended, we do not include $\chi_{t}$ in the DF-GLS test equation. DeJong et al. (1992) argued that many tests, including the ADF type test, have low power when the root of the autoregressive parameter is close to unity. ERS (1996) simulated the critical values of the test statistic in this latter setting for $T=\{50,100,200, \infty\}$, in particular for an infinite sample. The results presented in ERS (1996) suggest that GLS local detrending yields substantial power gains over the standard ADF unit root test constructed as Eq. (6).

\subsection{Cointegration Tests}

A linear combination of two or more non-stationary series may be stationary (Engle and Granger 1987), and such a stationary linear combination is regarded as a cointegrating equation that can be interpreted as a long-run equilibrium relationship among those variables - that is, the non-stationary time series are cointegrated (Chang and Lee 2015). The purpose of the cointegration tests is used to determine whether a group of nonstationary series are cointegrated or not (Lee 2013). As explained below, the presence of a cointegrating relation forms the basis of the vector error correct (VEC) specification. Thus, we employ the VAR based cointegration tests using the methodology developed in Johansen (1988, 1994).

Consider a VAR of order $k$; the test hypothesis is formulated as the restriction for the reduced rank of $\Pi=H_{0}(r)=\Pi=\alpha \beta^{\prime}$. Based on Fig. 1, it is evident that all of the variables show rising trends. At the same time, the possibility for technological change is included in the time trend. Thus, we use Johansen's $(1988,1994)$ maximum likelihood approach to perform cointegration tests. A cointegrating equation may have intercepts and deterministic trends simultaneously which can be expressed in their first-difference vector error correct model (VECM) form as:

$$
\Delta Y_{t}=\mu_{0}++\varphi D_{t}+\Gamma_{1} \Delta Y_{t-1}+\cdots+\Gamma_{k-1} \Delta Y_{t-(k-1)}+\alpha \beta^{\prime} Y_{t-1}+\varepsilon_{t},
$$

where $\mathrm{Y}_{t}$ is the $n$-vector of the non-stationary I(1) variables which contain ELF and MEP, and $\mu$ is the vector of the constants. The $\Gamma^{\prime} s$ parameters can be estimated; $\Delta$ is the difference operator; and $\varepsilon_{t}$ is the vector of innovations. Granger's representation theorem states that if the coefficient matrix $\Pi=\alpha \beta^{\prime}$ has a reduced rank $r<n$, then there exist $n \times r$ matrices $\alpha$ and $\beta$, each with rank $r$ which contains ELF and MEP, where $r$ is the number of cointegration relations (the cointegrating rank), and $\beta$ is the cointegrating vector. The elements of $\alpha$ are known as the adjustment parameters in the VECM. Johansen's method estimates the $\Pi$ matrix from an unrestricted VAR and tests whether the restrictions implied by the reduced rank of $\Pi$ can be rejected. Further, given the results of the unit root tests, we use the Johansen (1988) and Johansen and Juselius (1990) technique to test for cointegration among the variables within a VEC model (Lee and Chang 2006). If a nonzero vector(s) is indicated by these tests, a stationary long-run relationship among the relevant variables is implied. Osterwald-Lenum (1992) provides the appropriate critical values required for these cointegration tests.

A VECM is a restricted VAR designed for use with a nonstationary series that is known to be cointegrated. The VECM has a cointegration relationship built on the specifications 

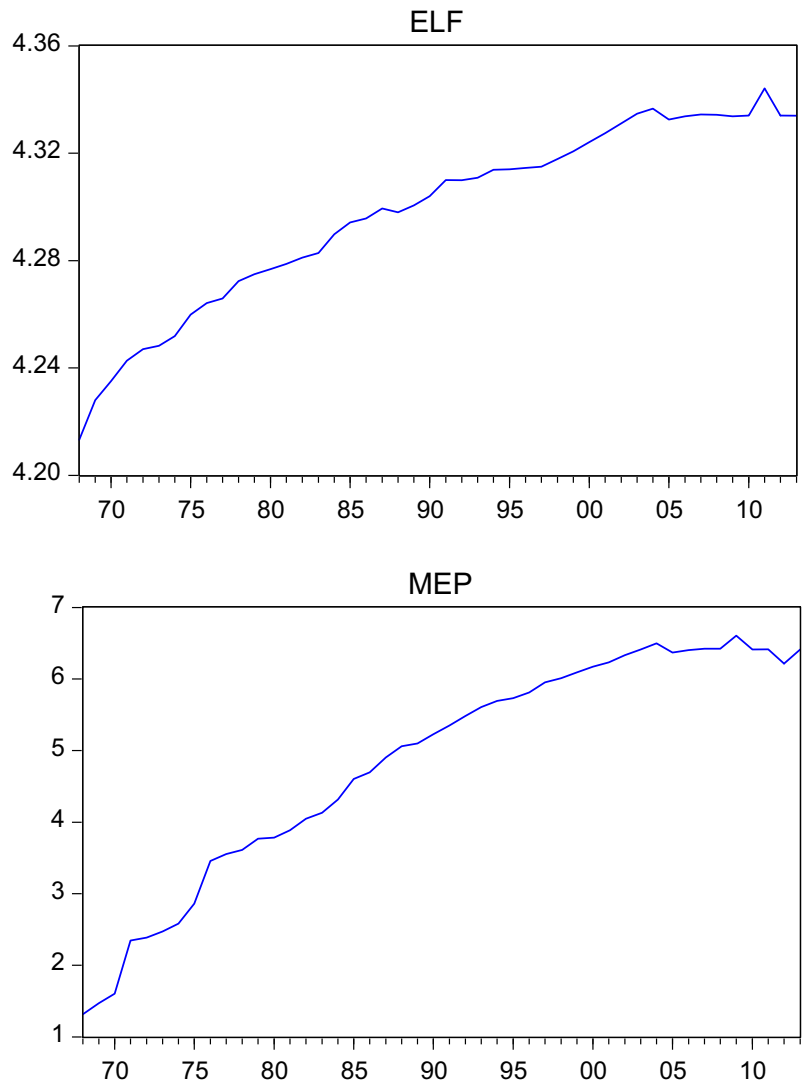

Fig. 1 Plots of ELF and MEP in 1968-2013

in such a way that it restricts the long-run behavior of the endogenous variables from converging to their cointegration relationships while allowing for short-run adjustment dynamics. The cointegration term is known as the error correction term since a deviation from long-run equilibrium is gradually corrected through a series of partial short-run adjustments. The corresponding VECM is:

$$
\begin{gathered}
\Delta E L F_{t}=\delta_{1}+\alpha_{1}\left(E L F_{t-1}-\beta M E P_{t-1}\right)+\lambda_{1} \Delta E L F_{t-1}+\varepsilon_{t} \\
\Delta M E P_{t}=\delta_{2}+\alpha_{2}\left(E L F_{t-1}-\beta M E P_{t-1}\right)+\lambda_{2} \Delta M E P_{t-1}+v_{t},
\end{gathered}
$$

where only the variable on the right-hand side is the error correction term$\left(E L F_{t-1}-\beta M E P_{t-1}\right)$. In the long-run equilibrium, this term is zero. However, if ELF and MEP deviate from the long run equilibrium, the error correction term is nonzero, and each variable adjusts to partially restore the equilibrium relationship. The coefficient $\alpha_{i}$ measures the speed of adjustment of the $i$ th endogenous variable towards the equilibrium. As stated above, if both variables are non-stationary but stationary in their linear combination, then the error-correction model rather than the standard Granger-causality test should be employed. 


\section{Results}

\subsection{Data Description}

The "Taiwan Supplement," published by the Department of Health in 2013, provides detailed background information about the current status of developments in medical treatment. It reports that Taiwan would rank 48th among the 192-member states of the WHO. On the level of population, in 2002, Taiwan had 22.52 million residents, and in the 1992-2012 period, the average annual growth rate of the population of Taiwan was $0.8 \%$, which was lower than the average annual growth rate of $1.5 \%$ of WHO member states for the same period. It is commonly thought that the low growth rate of Taiwan is primarily due to a low birth rate. In 2012, the percentage of total population aged over 60 years was $12.6 \%$, but the fertility rate in 2012 was only $1.3 \%$. In the last ten years in Taiwan, male life expectancy has increased by 1.4 years, which may explain why the national health expenditures (NHE) of this group accounted for $5.9 \%$ of GDP in 2011; however, this was higher than the world median of $5.5 \%$. The average annual per capita health expenditure of Taiwan was US\$ 743. In 2013, Taiwan had 192,611 medical personnel, 19,240 hospitals and clinics and 14 medical schools. Taiwan's life expectancy is 77.06 years, one of the highest globally.

In our study, all the data are annual observations of the variables, and the estimation is over the period 1968-2013 depending on the availability of the sample data. The data include the sum per thousands of registered nurses and physicians as medical personnel (MEP) as well as average life expectancy at birth (ELF). Following Barlow and Vissandjee (1999), Coile et al. (2002), Rivera and Currais (2003), and Fayissa and Gutema (2005), we specify life expectancy at birth as the health indicator. Compared with previous research, this paper differs in that medical personnel are taken as the health demand indicator. The data are taken from the Health and National Health Insurance Annual Statistics Information Service, Department of Health, and are in natural logarithms. From Fig. 1, we find deterministic trends in the two series, implying that the observed unit root behavior has been equated with persistence in the medical treatment system and health status. All of the matched cross-variable observations are plotted in Fig. 2, which visually depicts the relationships between MEP-ELF; indeed, there is a trend of co-movement.

\subsection{Empirical Results}

In the empirical process, we first perform the unit root tests. If all the test variables are nonstationary, we then look for a cointegrating relationship among them. We actually apply two unit root tests so as to obtain more accurate test results with intercept as well as intercept and trend. In so doing, we are able to avoid the pitfall of over-difference which can result when only the null hypothesis of a series with unit roots is examined, as seen in earlier literature. The two unit root tests of Sect. 3.1 we use are the ADF and the DF-GLS tests. Hence, in conducting the unit root tests, the selection of the optimal lag length and the selection of the optimal bandwidth have the greatest effects on the results. We select the lag parameters by the SBC criterion. Table 1 presents the unit root test results without break. We find that no matter by the ADF test or the DF-GLS test in levels, none of the series can reject the null of nonstationarity except for MEP with intercept $\left(\tau_{\mu}\right)$, but the reverse in first difference with intercept and trend $\left(\tau_{\tau}\right)$ in the ADF and DF-GLS tests 


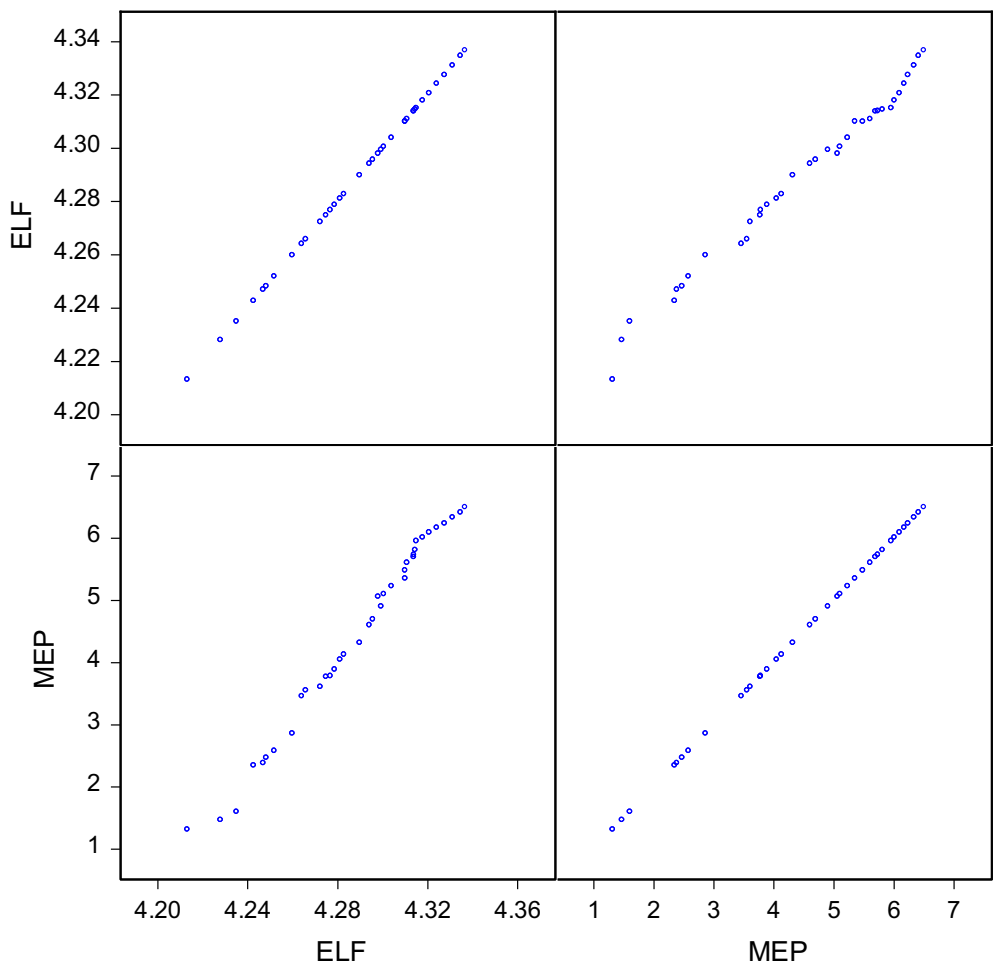

Fig. 2 Plots of matrix of all pairs MEP and ELF

Table 1 Unit root tests without break

\begin{tabular}{llllll}
\hline Variable & ELF & & \multicolumn{2}{l}{ MEP } \\
\cline { 2 - 3 } \cline { 5 - 6 } & $\tau_{\mu}$ & $\tau_{\tau}$ & & $\tau_{\mu}$ & $\tau_{\tau}$ \\
\hline ADF test & & & & \\
$\quad$ Levels & $-1.19(0)$ & $-1.40(0)$ & & $-3.871(4)^{* *}$ & $-0.274(8)$ \\
$\quad$ First differences & $-5.94(0)^{* *}$ & $-6.13(0)^{* *}$ & & $-2.872(3)^{* *}$ & $-4.792(3)^{* *}$ \\
DF-GLS test & & & & $-0.721(9)$ & $-2.885(0)^{* *}$ \\
$\quad$ Levels & $-0.80(0)$ & $-2.02(0)$ & & $-1.342(5)$ & $-4.470(3)^{* *}$ \\
First differences & $-1.07(1)$ & $-3.91(0)^{* *}$ & & $-1.342(5)$
\end{tabular}

$\tau_{\mu}$ is the $t$-statistic for testing the significance of $\alpha_{2}$ when a time trend is not included in Eq. (2), and $\tau_{\tau}$ is the $t$-statistic for testing the significance of $\alpha_{2}$ when a time trend is included in Eq. (2). The DF-GLS test is a linear unit-root test proposed by Elliott et al. (1996). The numbers in parentheses are the lag order in the $\mathrm{ADF}$ and DF-GLS tests. The lag parameters are selected on the basis of the SBC

** Significance at the $5 \%$ level

accepts the alternative hypothesis with the nonexistence of the unit root. The findings from the unit root tests clearly indicate that the variables are non-stationary.

However, the above standard unit root tests, which result in the non-rejection of a unit root, may be suspect when the sample under consideration incorporates medical events 
capable of causing shifts in regime since inaccurate conclusions could be drawn if the null hypothesis is not rejected. The presence of structural breaks is a common problem in macroeconomic series as they are normally caused by exogenous shocks or regime changes in economic events. If the empirical findings show stationarity, then the results can indicate that most shocks to these series are temporary and soon converge while controlling for those breaks. In order to take a possible shift in regime into account in a unit root test, Zivot and Andrews (1992; hereafter ZA) developed a test that allows for an endogenous structural break. As shown in Table 2, a test with the ZA approach unanimously shows that all of the variables are non-stationary. As for the structural break points for ELF and MEP, from Fig. 3 with intercept and trend, we note that the plot of the series for levels as well as first difference indicates that the data might very well have a structural break or even more than one.

From Table 2, it is clearly apparent in 1995. In all likelihood, this reflects the fact that Taiwan's compulsory universal health insurance scheme was implemented in that year. Another interesting phenomenon is that break for ELF with intercept is also found in 2000 right after the 921 Chi-Chi earthquake, a devastating event that struck in September, 1999 and caused the death of thousands in central Taiwan. From the 1950s when Taiwan was administering its public health care program with financial aid from the U.S., and in the 1970s when large enterprises began to were participating in the management of medical treatment programs. Added to this, a large number of new, well-equipped medical schools were opened to train additional medical personnel and help meet growing market requirements. Additionally, Rivera and Currais (2003) maintain that the overall state of health of the population depends on many factors associated with economic development. In this regard, it should be pointed out that Taiwan passed through quite a few economic milestones in succession, including the implementation of an expansionary plan in its export trade policy in the 1960s, which helped it lay the foundation for its rather startling economic development to take off in the 1970s (Lee and Chang 2005). There is no doubt that these contributed to the rise in the demand for medical personnel in Taiwan. These factors also explain why there were more breaks in MEP in the 1970s and 1980s.

Our next procedure is to examine the existence of a cointegration relationship among variables if they are non-stationary. However, before applying Johansen's (1988) maximum likelihood cointegration tests, in order to ensure that the errors are approximately white noise but still small enough to allow estimations to be made, we must first select the appropriate number of lag lengths (Ghali and El-Sakka 2004). For this reason, when selecting the number of lag periods, it is necessary to perform and pass residual misspecification tests using the VAR model.

Table 2 Zivot and Andrews (1992) unit root tests

\begin{tabular}{|c|c|c|c|c|c|c|c|c|}
\hline \multirow[t]{3}{*}{ Variable } & \multicolumn{4}{|l|}{ Levels } & \multicolumn{4}{|c|}{ First differences } \\
\hline & \multicolumn{2}{|l|}{$\tau_{\mu}$} & \multicolumn{2}{|l|}{$\tau_{\tau}$} & \multicolumn{2}{|l|}{$\tau_{\mu}$} & \multicolumn{2}{|l|}{$\tau_{\tau}$} \\
\hline & $t_{\hat{\alpha}}\left(\hat{\lambda}_{\text {inf }}\right)$ & Break & $t_{\hat{\alpha}}\left(\hat{\lambda}_{\text {inf }}\right)$ & Break & $t_{\hat{\alpha}}\left(\hat{\lambda}_{\mathrm{inf}}\right)$ & Break & $t_{\hat{\alpha}}\left(\hat{\lambda}_{\text {inf }}\right)$ & Break \\
\hline ELF & $-3.83(2)$ & 1992 & $-3.31(2)$ & 1985 & $-5.31(2)^{* *}$ & 2000 & $-5.38(2)^{* *}$ & 1995 \\
\hline MEP & $-4.61(2)$ & 1976 & $-4.20(2)$ & 1989 & $-5.88(2) * *$ & 1978 & $-5.842(2)^{* *}$ & 1979 \\
\hline
\end{tabular}

Numbers in parentheses are the lag order. The lag parameters are selected on the basis of the SBC

** Significance at the $5 \%$ level 

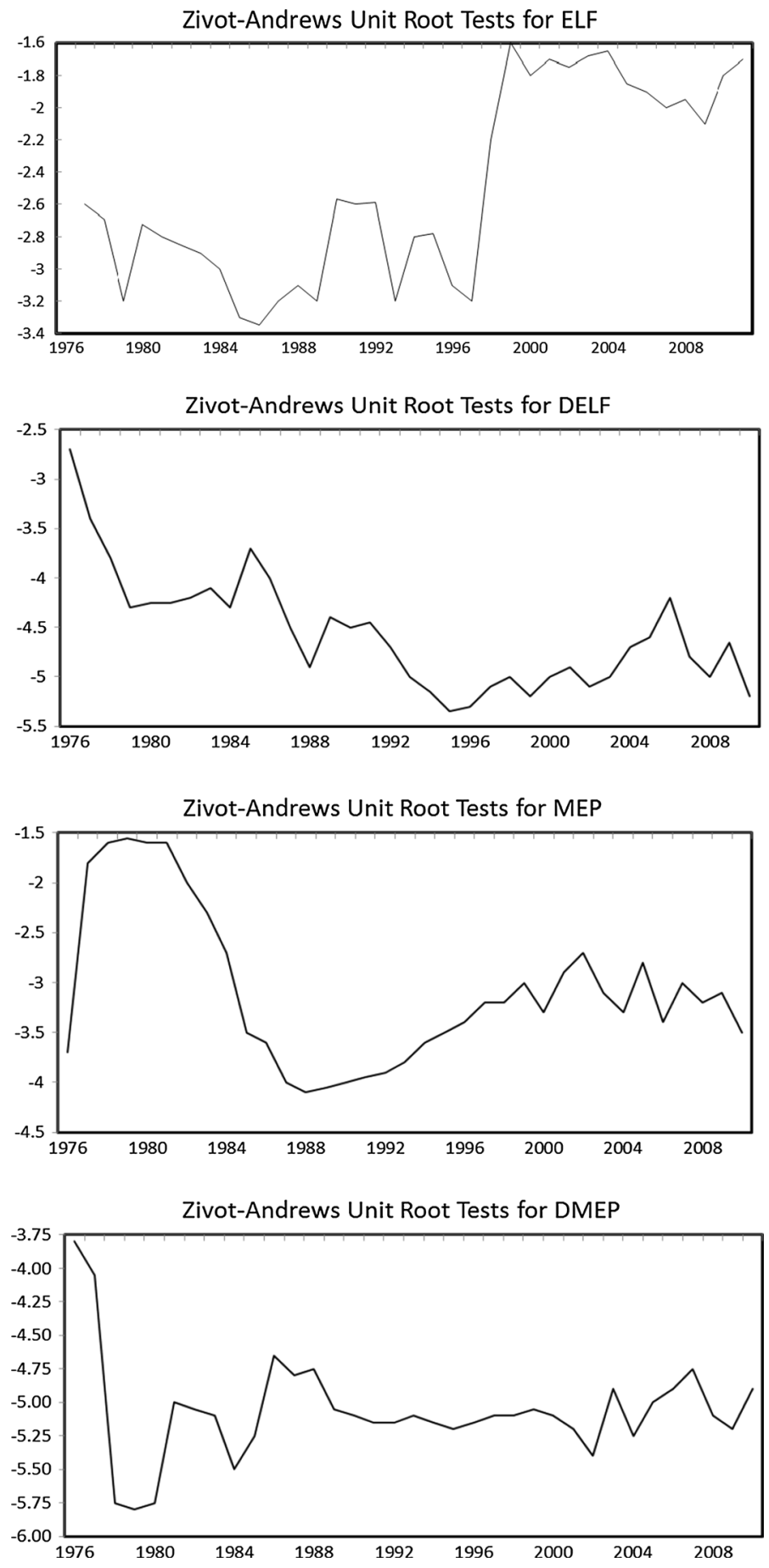

Fig. 3 Plots of series with intercept and trend for the ZA (1992) tests 
We employ many different lag length selection criteria to determine the autoregressive (AR) lag lengths of the time series variables based on numerous economic studies. Briefly, an AR process of lag length $p$ refers to a time series in which the current value is dependent on its first $p$ lag value and is normally denoted by $\operatorname{AR}(k)$. Note that the AR lag length $k$ is always unknown, and therefore, it has to be estimated using various lag length selection criteria, such as the sequential modified likelihood ratio (LR) test, the final prediction error (FPE) method (Akaike 1969), Akaike's information criterion (AIC) (Akaike 1974), Schwarz' information criterion (SBC) (Schwarz 1978) and the Hannan-Quinn criterion (HQ) (Hannan and Quinn 1979). ${ }^{5}$

We employ the FPE, AIC, SBC, and HQ to determine the number of lags based on our decision on the sequential modified likelihood ratio (LR) test and various information criteria that should be used in the VAR. Subsequently, we introduce a sufficient number of lags to eliminate the serial correlation of the residuals. From the test results reported in Table 3, we select lag 1. Using this lag-length, we perform the test for the absence of serial correlation in the residuals in the VAR to make sure that none of them violates the standard assumptions of the model. The Lagrange multiplier (LM) tests the statistics of residual serial correlation up to the specified order $k{ }^{6}$ To this end, we use the VAR residual serial correlation LM test. Under the null hypothesis of no serial correlation up to lag $k$, the statistic is approximately distributed $\chi^{2}$ with degrees of freedom $h^{2}(k-p)$, where $p$ is the VAR lag order, and $h$ is the number of endogenous variables. The results indicate that with lags 1,4 , and 8 , the residuals in the VAR are approximately independent identically normally distributed, and these are presented in Table $4 .^{7}$ On the grounds that the null of the VAR residual LM tests for autocorrelations has no residual autocorrelations up to lag $k$, we are able to confirm that the residuals of the VAR model do not exhibit serial correlation; thus, the optimum number of lag periods is 1 .

In the cointegration tests, the null hypothesis $r=0$ is tested against the alternative that $r=1, r=1$ against the alternative $r=2$, and so forth. The cointegration results of testing the number of cointegration vectors based on the maximum eigenvalue $\left(\lambda_{\max }\right)$ and the trace $(\operatorname{Tr})$ of the stochastic matrix in the multivariate framework are reported in Table 5; also presented at the $5 \%$ critical values which are limited because of the small sample size (Pesaran et al. 2001). In Table 5, the results indicate that, at most, there is one cointegration relationship since the null hypotheses of $r=0$ is clearly rejected for both $\lambda_{\max }$ and $\operatorname{Tr}$ statistics, but $r=1$ cannot be rejected at the $5 \%$ significance level. This strongly suggests that there is one cointegration vector between ELF and MEP. This is concrete evidence that a long-run equilibrium exists between life expectancy at birth and medical personnel in Taiwan. Importantly, the variables tend to evolve together over time. The results in Table 5 suggest that the number of statistically significant normalized cointegration vectors is equal to 1 as follows:

\footnotetext{
5 These criteria are discussed in Lütkepohl (1991). Mathematically, we identify the AR lag length $k$ based on certain rules, such as the lag length selection criteria. In this study, we conduct each and every one of the lag length tests.

${ }^{6}$ We compute the test statistics for lag order by running an auxiliary regression of the residuals on the original regressors on the right-hand side and the lagged residuals; the formula for the LM statistics is presented in Johansen (1995).

7 First of all, the method involves performing a test with a lag of one period. If it is not possible to pass the serial correlation test, then the number of lagged periods should be increased until the shortest period that causes the residuals to be white noise is found (Johansen and Juselius 1990).
} 
Table 3 VAR lag order selection criteria

\begin{tabular}{lrllll}
\hline Lag & LR & FPE & AIC & SBC & HQ \\
\hline 1 & $176.5323^{\mathrm{a}}$ & $5.46 \mathrm{e}-08^{\mathrm{a}}$ & $-11.04781^{\mathrm{a}}$ & $-10.77845^{\mathrm{a}}$ & $-10.95595^{\mathrm{a}}$ \\
2 & 2.675309 & $6.32 \mathrm{e}-08$ & -10.90477 & -10.45584 & -10.75167 \\
3 & 3.486830 & $7.09 \mathrm{e}-08$ & -10.79862 & -10.17011 & -10.58428 \\
\hline
\end{tabular}

$L R$ sequential modified LR test statistics, FPE final prediction error, AIC Akaike information criterion, $S B C$ Schwarz information criterion, $H Q$ Hannan-Quinn information criterion

${ }^{a}$ Lag order selected by the criterion

Table 4 VAR residual serial correlation LM tests

\begin{tabular}{llr}
\hline Lags & LM-stat & Prob. \\
\hline 1 & 6.780217 & 0.1480 \\
4 & 2.207865 & 0.6976 \\
8 & 2.584682 & 0.6295 \\
\hline
\end{tabular}

The LM statistic is asymptotically distributed $\chi^{2}$

Table 5 Johansen's cointegration tests

\begin{tabular}{lcc}
\hline Hypothesized number of cointegration & Statistic & 0.05 critical value \\
\hline Max-Eigen & & 16.64 \\
$r=0$ & $19.59 * *$ & 4.07 \\
$r=1$ & 3.82 & \\
Trace statistic & & 15.12 \\
$r=0$ & $15.77^{* *}$ & 4.07 \\
$r=1$ & 3.82 & \\
\hline
\end{tabular}

The $5 \%$ finite sample critical values are constructed from the asymptotic critical values from OsterwaldLenum (1992) using the method of Cheung and Lai (1993). $r$ is cointegration rank

$$
E L F=0.052 M E P-4.532 .
$$

Based on the above cointegration vector, it is clear that the elasticity of ELF with respect to MEP is 0.052 , implying that to raise MEP by $10 \%$ is to induce $0.52 \%$ in ELF. More to the point, that, in the long run, the variable medical personnel has a positive effect on life expectancy at birth. Given the signs of the vector cointegration components, the above relationships can be used as the error correction mechanism in the VAR model.

In the long run, according to the result of the cointegration relationships between life expectancy at birth and the number of registered nurses and physicians in Taiwan, the Taiwan government still has to keep on improving the public health care program by continuing to try to implement the compulsory universal health insurance scheme more and more efficiently and by training additional and retraining existing medical personnel. This 
signifies that the responsibility of governments should be redirected so that it focuses on thoroughly developing the medical treatment environment, on building and nurturing an improved health care system and on enhancing the functions of medical professionals, with the latter being the major key to the betterment of the population's, health quality of life and general welfare.

In order to gain a better insight into the interrelationships between the variables, we perform a VECM analysis. Engle and Granger (1987) provided a test of causality which takes into account the information provided by the cointegration properties of variables. Based on our test results, once the variables are cointegrated, then in the short run, any deviation from the long-run equilibrium path feeds back in the form of future changes in order to force the movement towards the long-run equilibrium. The cointegration vectors, from which the error-correction terms are derived, each indicates an independent direction where a stable and meaningful long-run equilibrium exists. The coefficients of the error correction terms, however, represent the extent to which the long-run disequilibrium in the dependent variables is corrected in each short-run period; furthermore, the lag of the explanatory variables significantly differs from zero. Besides this, the VECMs have the cointegrating relationships built on the specifications; thus, prevents the long-run behavior of the endogenous variables from converging to the cointegration relationships of those endogenous variables, but they allow for short-run dynamic adjustments. The estimates from our VECMs are presented in Table 6.

In the procedure of the VECMs, we first must determine the number of lags using test regressions. The VAR lag order selection criteria are reported in Table 3. We select the lag number 1. Several findings are noteworthy. The coefficient of $E C_{t-1}$ in the $\triangle \mathrm{MEP}$ error correction equation has the highest value of 0.589 (absolute value) and is the most significant, indicating that, when the short-run disequilibrium among the variables is adjusted to the long run equilibrium, medical personnel plays a major role. In addition, the coefficient of the error correction term in $\triangle E L F$ is significant $(0.009$, absolute value), reflecting the fact that when the medical system in the short-term disequilibrium, medical personnel and life expectancy can restore equilibrium to the long-run, but the speed of adjustment is the most rapid when medical personnel are involved. This again demonstrates the important position held by medical personnel in the medical care system of Taiwan. In terms of lag, the coefficient of $\Delta E L F_{t-1}$ is 2.788 in the $\triangle M E P_{t}$ equation, and this is at the $5 \%$ significance level. But the relationship for the coefficient of $\triangle \mathrm{MEP}_{t-1}$ in the $\triangle E L F_{t}$ error correction equation cannot be determined. These results are consistent with those of Rivera and Currais (2003) — that is, in the short run, increasing in life expectancy may occur prior to that for medical personnel. Alubo (2001) has shown that developments in health care are irrevocably among the most significant human development indicators; therefore, a country with a relatively high growth rate may wish to strengthen its national health care standards by ameliorating the skills of teaching and retraining and by ensuring the best skilled care procedures are accessible for health care professionals to provide. From this perspective, medical personnel play the major role in filling the health needs of the population in Taiwan.

So far, our analysis has essentially been restricted to within sample tests. To gauge the relative strength of these results based on the causality tests, we now shock the system and partition the forecast error variance of each of the variables. Variance decompositions show the proportion of forecast error variance for each variable due to its own innovations and shocks of other system variables that capture both the direct and indirect effects of the variables in the system. Most previous studies based on similar modeling, however, have been subject to the orthogonality problem, as described by Lütkepohl (1991). In the 
Table 6 Vector error correction model estimates

\begin{tabular}{lll}
\hline Independent variable & $\Delta E L F_{t}$ & $\Delta M E P_{t}$ \\
\hline$E C_{t-1}$ & $-0.009^{* *}$ & $-0.589^{* *}$ \\
& $(-2.064)$ & $(-2.385)$ \\
Constant & $0.003^{* *}$ & $0.114^{* *}$ \\
& $(3.630)$ & $(2.450)$ \\
$\Delta E L F_{t-1}$ & 0.094 & $2.788^{* *}$ \\
$\Delta M E P_{t-1}$ & $(0.495)$ & $(2.540)$ \\
& -0.003 & $-0.426^{* *}$ \\
& $(-1.046)$ & $(-2.864)$ \\
\hline
\end{tabular}

traditional method of Sims (1980), results are subject to a change of the order of variables in the VAR system. Therefore, we use the advanced generalized forecast error variance decomposition (GVDC) and generalized impulse response (GIRF) techniques developed by Koop et al. (1996) and Pesaran and Shin (1998). ${ }^{8}$ We determine the relationship between the forecast error variance in ELF and that in MEP. The new generalized methodologies are not sensitive to changes of the order of variables. Given this, the forecast error variance in any variable is decomposed into the proportion attributed to each of its random shocks.

While GIRF traces the effects of a shock of one endogenous variable on other variables in the VAR system, GVDC separates the variation of an endogenous variable into the component shocks in the VAR model. That is, GVDC can offer the proportion of the movements in the dependent variable due to their own shock, versus shocks to the other variable. Therefore, GVDC is likely to be regarded as an out-of-sample causality analysis that provides information regarding the relative importance of each random innovation in affecting the variables in the VAR system (Lee et al. 2013).

Table 7 reports the case of Taiwan. After 1 year, $90 \%$ or more of the forecast error variances of ELF are accounted for the changes by itself. The forecast error variance of ELF is accounted for by MEP innovations that rises only about $1.6 \%$ in up to 10 years. We also find that MEP is explained by nearly $60 \%$ of the innovations in ELF in up to 10 years and that only $40 \%$ is explained by itself.

Not only does impulse response function represent a shock to and directly affect the $i$ th variable, but they are also transmitted to all of the other endogenous variables through the dynamic (lag) structure of the VAR. In other words, an impulse response function traces the effect of a one-time shock to one of the innovations on current and future values of the endogenous variables (Lee et al. 2013). We follow Pesaran and Shin (1998) to construct an orthogonal set of innovations that does not depend on the order of variables. This reflects the impulse responses from an innovation to the $i$ th variable. Table 8 reports the cumulative generalized impulse responses of ELF and MEP. Evidently, the net effect of ELF on ELF and MEP is positive for Taiwan over this period. In addition, the same results are found for the impact of MEP on [MEP, ELF], and the net effect of MEP on ELF is larger than that of ELF on MEP, which again attests to the fact that medical personnel hold the

\footnotetext{
${ }^{8}$ Using vector autoregressions (VARs) models as Granger causality tests, impulse response functions, and variance decompositions, which combine with the advantages of good forecasting capabilities, all are endogenous variables in the system, and it is very easy to test for causality between variables (Lee et al. 2013). More importantly, Sims (1980) and others argue that this framework provides a systematic way to capture abundant dynamics and comovements in bivariate models, and the test statistics provide coherent approach in forecasting and policy analysis in accordance with health demand and production function.
} 
Table 7 Generalized forecast error variance decomposition results

The forecast is ten years.

Standard errors are from 10,000

Monte Carlo simulations

\begin{tabular}{|c|c|c|c|}
\hline \multirow[t]{2}{*}{ Dependent variable } & \multirow[t]{2}{*}{ Horizon } & \multicolumn{2}{|c|}{ Explained by innovations in } \\
\hline & & ELF & MEP \\
\hline \multirow[t]{10}{*}{ ELF } & 1 & 100.0000 & 0.000000 \\
\hline & 2 & 99.34804 & 0.651963 \\
\hline & 3 & 99.51035 & 0.489651 \\
\hline & 4 & 99.21440 & 0.785601 \\
\hline & 5 & 98.88940 & 1.110597 \\
\hline & 6 & 98.69044 & 1.309561 \\
\hline & 7 & 98.57539 & 1.424612 \\
\hline & 8 & 98.49815 & 1.501847 \\
\hline & 9 & 98.43819 & 1.561810 \\
\hline & 10 & 98.38880 & 1.611205 \\
\hline \multirow[t]{10}{*}{ MEP } & 1 & 10.91618 & 89.08382 \\
\hline & 2 & 30.87197 & 69.12803 \\
\hline & 3 & 48.67252 & 51.32748 \\
\hline & 4 & 59.30298 & 40.69702 \\
\hline & 5 & 65.60114 & 34.39886 \\
\hline & 6 & 69.69214 & 30.30786 \\
\hline & 7 & 72.61581 & 27.38419 \\
\hline & 8 & 74.84311 & 25.15689 \\
\hline & 9 & 76.60044 & 23.39956 \\
\hline & 10 & 78.01713 & 21.98287 \\
\hline
\end{tabular}

key position in Taiwan's medical care system. Medical care personnel do indeed make outstanding contributions to the health care system, and this, coupled with increased longevity explains the highly elevated demand for medical personnel. Based on the findings of the impulse response functions, except for shocks of MEP that have a positive initial impact on ELF, we also find that similar innovations and shocks from ELF to MEP, respectively.

In accordance with the empirical findings-including cointegration tests, a vector error correct model, generalized forecast error variance decomposition, and impulse response functions, the results deliver one important message: medical care personnel indeed contribute to increases life expectancy, whereas, this is the casual evident as longevity also promote more medical personnel needs in Taiwan. Therefore, according to health demand function as proposed by Grossman (1972) or health production function mentioned by Waldmann (1992), our paper confirms that both nurses and physicians are valued input factors in the health care system of Taiwan. Similar evidence is discovered in individual countries, such as Costa Rica, Sri Lanka, and Egypt (Hertz et al. 1994), Israel (Chernichovsky and Anson 2005), Japna (Hickson 2009), and most of Sub-Saharan Africa countries (Ssozi and Amlan 2015). We believe that this finding will make readers understand the key role of medical personnel commonly in the worldwide but not only in Taiwan. 
Table 8 Cumulative generalized impulse response functions

\begin{tabular}{lrl}
\hline Period & \multicolumn{1}{l}{ ELF } & MEP \\
\hline Accumulated response of & ELF & \\
1 & 0.002045 & 0.000676 \\
2 & 0.004167 & 0.001152 \\
3 & 0.006069 & 0.001836 \\
4 & 0.007798 & 0.002639 \\
5 & 0.009438 & 0.003450 \\
6 & 0.011028 & 0.004225 \\
7 & 0.012571 & 0.004964 \\
8 & 0.014066 & 0.005673 \\
9 & 0.015511 & 0.006359 \\
10 & 0.016906 & 0.007022 \\
Accumulated response of & $M E P$ & \\
1 & 0.038815 & 0.117481 \\
2 & 0.108403 & 0.181847 \\
3 & 0.193639 & 0.221181 \\
4 & 0.279471 & 0.255635 \\
5 & 0.360953 & 0.291243 \\
6 & 0.438286 & 0.327522 \\
7 & 0.512539 & 0.363142 \\
8 & 0.584295 & 0.397517 \\
9 & 0.653723 & 0.430607 \\
10 & 0.720858 & 0.462522 \\
\hline & &
\end{tabular}

\section{Conclusions and Policy Implications}

The importance of medical resources-from medical personnel care to primary care services - has been widely acknowledged (Waldmann 1992); nevertheless, it still needs to pay much attention to the ongoing professional development of nurses and physicians. Apart from this, more specifically, the training of nurses and doctors must be fully relevant to clinical practices as this would the quality of health care and the general state of health of all citizens (Rodriguez et al. 1999). Fayissa and Gutema's (2005) recent results suggest that an increase in income per capita, a decrease in the illiteracy rate, and an increase in food availability are strongly associated with an improvement in life expectancy at birth. We cannot but agree, of course, finding more effective treatments to eradicate diseases, and to increase life expectancy is the new major challenge that we will face.

This empirical study investigates the relationship between two health indicators, medical personnel, and life expectancy in Taiwan during the 1968-2013 period. We apply unit root tests and the cointegration approach to empirically investigate the long-run relationships between medical personnel (MEP), i.e., registered nurses and physicians, and life expectancy (ELF). On the weight of the empirical results, we conclude that there is long-run equilibrium between two variables in Taiwan. The VECM approach indicates that if there is a short-run disequilibrium among the variables, medical personnel play the crucial role to ensure the restoration of the long-run equilibrium. In addition, with medical personnel, the speed of adjustment is the most rapid. Based on our findings, almost all of 
the forecast error variances for life expectancy is accounted for by itself, but medical personnel accounts for a larger percentage of the forecast error variance by life expectancy, and of course, shows that increased longevity increases the demand for medical personnel. Finally, with the impulse response functions, all variables in the VAR model appear to have a positive effect on each other.

We point out some important policy implications in the following. Firstly, we find the long-run relationship between medical personnel and life expectancy in Taiwan, implying that the Taiwan government still has to keep on improving the public health care program by continuously trying to implement the compulsory universal health insurance scheme more and more efficiently and by training additional and retraining existing medical personnel. Next, because medical personnel occupy the most important position in the medical care system of Taiwan, the government is urged to pay much attention to carefully establish and enhance medical treatment policy when higher life expectancy is expected by Taiwanese; more specifically, the related policies ought to ensure work flexibility so that adjustments to changes in the clinical environment can be made quickly due to the sound National Health Insurance System in Taiwan. Finally, the results from Granger causality tests, impulse response functions, and variance decompositions indicate that the administrative policy should provide more on-going training and retraining to medical personnel. Besides keeping health care costs low, policies should be directed such that Taiwan's authorities have better control over and maintain a low patient-to-health care worker ratio to ensure a high standard of medical care. Added to this, related policies should provide provisions to equip hospitals and other facilities with the most up-to-date medical technology etc. Much of this should, at least in part, be the shared responsibility of corporations.

Overall, the authorities need to prompt a great deal of research to generate new knowledge about the cross-sectoral relationships that might be useful for policy-makers as they develop and implement policies for improving public health. In this paper, we conduct such an analysis to determine the importance of the demand for health care and to explain the variations in life expectancy of the people of Taiwan.

Acknowledgments The authors are grateful the comments for Editor and two anonymous referee for our paper.

\section{References}

Akaike, H. (1969). Fitting autoregressions for prediction. Annals of the Institute of Statistical Mathematics, $21,243-247$.

Akaike, H. (1974). A new look at the statistical model identification. IEEE Transactions on Automatic Control, AC-19, 716-723.

Alubo, O. (2001). The promise and limits of private medicine: Health policy dilemmas in Nigeria. Health Policy and Planning, 16, 313-321.

Anand, S., \& Ravallion, M. (1993). Human development in poor countries: On the role of private incomes and public services. Journal of Economic Perspectives, 7, 133-150.

Arestis, P., Demetriades, P. O., \& Luintel, K. B. (2001). Financial development and economic growth: The role of stock market. Journal of Money, Credit, and Banking, 33, 16-41.

Auster, R., Leveson, I., \& Sarachek, D. (1969). The production of health: An exploratory study. Journal of Human Resources, 4, 411-436.

Barlow, R., \& Vissandjee, B. (1999). Determinants of national life expectancy. Canadian Journal of Development, 20, 9-29.

Bhargava, A. (1997). Nutritional status and the allocation of time in Rwandese households. Journal of Econometrics, 77, 277-295. 
Bloom, D., Canning, D., \& Sevilla, J. (2004). The effect of health on economic growth: A production function approach. World Development, 32, 1-13.

Bloom, G., \& Xingyuan, G. (1997). Health sector reform: Lessons from China. Social Science Medical, 45, $351-360$.

Borg, V., \& Kristensen, T. (2000). Social class and self-rated health: Can the gradient be explained by differences in life style or work environment? Social Science and Medicine, 51, 1019-1030.

Chang, C. P., \& Lee, C. C. (2015). Do oil spot and futures prices move together? Energy Economics, 50, 379-390.

Chen, P. F., Lee, C. C., \& Zeng, J. H. (2014). The relationship between spot and futures oil prices: Do structural breaks matter? Energy Economics, 43, 206-217.

Chernichovsky, D., \& Anson, J. (2005). The Jewish-Arab divide in life expectancy in Israel. Economics \& Human Biology, 3(1), 123-137.

Cheung, Y. W., \& Lai, K. S. (1993). Finite-sample sizes of Johansen's likelihood ratio tests for cointegration. Oxford Bulletin of Economics and Statistics, 55(3), 313-328.

Chiang, T. (1997). Taiwan's 1995 health care reform. Health Policy, 39, 225-239.

Coile, C., Diamond, P., Gruber, J., \& Jousten, A. (2002). Delays in claiming social security benefits. Journal of Public Economics, 84, 357-385.

Contoyannis, P., \& Jones, A. (2004). Socio-economic status, health and lifestyle. Journal of Health Economics, 23, 965-995.

Currais, L., \& Rivera, B. (1999). Income variation and health expenditure: Evidence for OECD countries. Review of Development Economics, 3, 258-267.

DeJong, D., Nankervis, J., Savin, N., \& Whiteman, C. (1992). The power problem of unit root tests in time series with autoregressive errors. Journal of Econometrics, 53, 323-343.

Dickey, D., \& Fuller, W. (1979). Distribution of the estimators for autoregressive time series with a unit root. Journal of the American Statistical Association, 74, 427-431.

Easterly, W., \& Rebelo, S. (1993). Fiscal policy and economic growth. Journal of Monetary Economics, 32, 417-458.

Elliott, G., Rothenberg, T., \& Stock, J. H. (1996). Efficient tests for an autoregressive unit root. Econometrica, 64, 813-836.

Engle, R., \& Granger, C. (1987). Co-integration and error correction representation: Estimation and testing. Econometrica, 55, 251-267.

Fayissa, B., \& Gutema, P. (2005). Estimating a health production function for Sub-Saharan Africa (SSA). Applied Economics, 37, 155-164.

Fuchs, V. (1986). The health economy (1st ed.). Cambridge, MA: Harvard University Press.

Ghali, K. H., \& El-Sakka, M. I. T. (2004). Energy use and output growth in Canada: A multivariate cointegration analysis. Energy Economics, 26, 225-238.

Grossman, M. (1972). On the concept of health capital and the demand for health. Journal of Political Economy, 80, 223-255.

Hannan, E. J., \& Quinn, B. G. (1979). The determination of the order of an autoregression. Journal of the Royal Statistical Society: Series B, 41, 190-195.

Hertz, E., Hebert, R., \& Landon, J. (1994). Social and environmental factors and life expectancy, infant mortality, and maternal mortality rates: Results of a cross-national comparison. Social Science \& Medicine, 39 (1), 105-114.

Hickson, K. (2009). The contribution of increased life expectancy to economic development in twentieth century Japan. Journal of Asian Economics, 20(4), 489-504.

Johansen, S. (1988). Statistical analysis of cointegration vectors. Journal of Economic Dynamics and Control, 12, 231-254.

Johansen, S. (1994). The role of the constant and linear terms in cointegration analysis of nonstationary variables. Econometric Reviews, 13, 205-229.

Johansen, S. (1995). A statistical analysis of cointegration for I(2) variables. Econometric Theory, 11, 25-59.

Johansen, S., \& Juselius, L. (1990). Maximum likelihood estimation and inference on cointegration-With applications to the demand for money. Oxford Bulletin of Economics and Statistics, 52, 169-210.

Jones, C. I. (1995). Time series tests of eondogenous growth models. Quarterly Journal of Economics, 110, 495-525.

Kenkel, D. (1995). Should you eat breakfast? Estimates from health production functions. Health Economics, 4, 15-29.

Kerry, J. (2009). The contribution of increased life expectancy to economic development in twentieth century Japan. Journal of Asian Economics, 20, 489-504. 
Kindig, D. (1997). Purchasing population health: Paying for results. Ann Arbor: University of Michigan Press.

Koop, G., Pesaran, M. H., \& Potter, S. M. (1996). Impulse response analysis in nonlinear multivariate models. Journal of Econometrics, 74, 119-147.

Lantz, P., House, J., Lepkowski, J., Williams, D., Mero, R., \& Chen, J. (1998). Socioeconomic factors, health behaviours and mortality. Journal of the American Medical Association, 279, 1703-1708.

Lee, C. C. (2013). Insurance and real output: The key role of banking activities. Macroeconomic Dynamics, 17, 235-260.

Lee, C. C., \& Chang, C. P. (2005). Structure breaks, energy consumption, and economic growth revisited: Evidence from Taiwan. Energy Economics, 27, 857-872.

Lee, C. C., \& Chang, C. P. (2006). The long-run relationship between defence expenditures and GDP in Taiwan. Defence and Peace Economics, 17(4), 361-385.

Lee, C. C., Huang, W. L., \& Yin, C. H. (2013). The dynamic interactions among the stock, bond and insurance markets. North American Journal of Economics and Finance, 26, 28-52.

Lee, C. C., Tsong, C. C., \& Lee, J. F. (2014). Testing for the efficient market hypothesis in stock prices: International evidence from non-linear heterogeneous panels. Macroeconomic Dynamics, 18(4), 943-958.

Lu, J. F., \& Hsiao, W. C. (2003). Does universal health insurance make health care unaffordable? Lessons from Taiwan. Health Affairs, 22, 77-88.

Lütkepohl, H. (1991). Introduction to multiple time series analysis. New York: Springer.

McGinnis, J., \& Foege, W. H. (1993). Actual causes of death in the United States. Journal of the American Medical Association, 270, 2207-2212.

Miller, R., \& Freeh, H. I. (2000). Is there a link between pharmaceutical consumption and improved health in OECD countries. Pharmacoeconomics, 18(Supplement), 33-45.

Mullner, R., \& McNeil, D. (1986). Rural and urban hospital closures: A comparison. Health Affairs, 5, $131-141$.

Nelson, C. R., \& Plosser, C. I. (1982). Trends and random walks in macroeconomic time series: Some evidence and implications. Journal of Monetary Economics, 10, 139-162.

Newhouse, J. P. (1977). Medical care expenditure: A cross-national survey. The Journal of Human Rersources, 12, 115-125.

$\mathrm{Ng}, \mathrm{S} .$, \& Perron, P. (1995). Unit root tests in ARMA models with data-dependent methods for the selection of the truncation lag. Journal of the American Statistical Association, 90, 268-281.

Nolte, E., Scholz, R., Shkolnikov, V., \& McKee, M. (2002). The contribution of medical care to changing life expectancy in Germany and Poland. Social Science \& Medicine, 55(11), 1905-1921.

Osterwald-Lenum, M. (1992). A note with quantiles of the asymptotic distribution of the maximum likelihood cointegration rank test statistics. Oxford Bulletin of Economics and Statistics, 54, 461-472.

Pesaran, M. H., \& Shin, Y. (1998). Impulse response analysis in linear multivariate models. Economics Letters, 58, 17-29.

Pesaran, M. H., Shin, Y., \& Smith, R. J. (2001). Bounds testing approaches to the analysis of level relationships. Journal of Applied Econometrics, 16, 289-326.

Rivera, B., \& Currais, L. (2003). The effect of health investment on growth: A causality analysis. International Advances in Economic Research, 9, 312-323.

Rodriguez, R., Depuelles, P., \& Jovell, A. (1999). The Spanish health care system: Lessons for newly industrialized countries. Health Policy and Planning, 14, 164-173.

Rosenzweig, M., \& Schultz, T. P. (1983). Estimating a household production function. Journal of Political Economy, 91, 723-746.

Schwarz, G. (1978). Estimating the dimension of a model. Annals of Statistics, 6, 461-464.

Self, S., \& Grabowski, R. (2003). How effective is public health expenditure in improving overall health? A cross-country analysis. Applied Economics, 35, 835-845.

Shaw, J., Horrace, W., \& Vogel, R. (2005). The determinants of life expectancy: An analysis of the OECD health data. Southern Economic Journal, 71, 768-783.

Sims, C. A. (1980). Macroeconomics and reality. Econometrica, 48, 1-48.

Soubbotina, T., \& Sheram, K. (2000). Beyond economic growth: Meeting the challenges of global development. Washington: The World Bank published.

Ssozi, J., \& Amlan, S. (2015). The effectiveness of health expenditure on the proximate and ultimate goals of healthcare in Sub-Saharan Africa. World Development, 76, 165-179.

Thornton, J. (2002). Estimating a health production function for the U.S.: Some new evidence. Applied Economics, 34, 59-62.

Waldmann, R. (1992). Income distribution and infant mortality. Quarterly Journal of Economics, 107, 1283-1302. 
Wheeler D. (1980). Human resource development and economic growth in developing countries: A simultaneous model. World Bank, Staff working paper 407.

Wikström, L., Eriksson, K., Arestedt, K., Fridlund, B., \& Broström, A. (2013). Healthcare professionals' perceptions of the use of pain scales in postoperative pain assessments. Applied Nursing Research, 27, 53-58.

Younga, F., \& Rodriguez, E. (2005). Types of provincial structure and population health. Social Science and Medicine, 60, 87-95.

Zivot, E., \& Andrews, D. W. (1992). Further evidence on the great crash, the oil-price shock, and the unitroot hypothesis. Journal of Business and Economic Statistics, 10, 251-270. 